\title{
ENSINO MÉDIO: ATALHO PARA O PASSADO*
}

\author{
Luiz Antônio Cunha ${ }^{1}$
}

RESUMO: Este artigo analisa a reforma do Ensino Médio proposta pela Medida Provisória no 746/2016, na perspectiva das políticas anteriores, tais como as expressas na Lei no 5692/1971 e no Decreto no 2208/1997: a fusão dos ramos curriculares (pela lei) ou sua distinção (pelo decreto) tinham como função a contenção da demanda de Ensino Superior. No caso da medida provisória, essa função deriva, também, de uma particular crise das instituiçóes privadas de Ensino Superior, que tem levado a uma inédita centralização empresarial e concentração do capital.

Palavras-chave: Política educacional. Discriminação social. Ensino Médio. Ensino Superior.

\section{HIGH SCHOOL: SHORTCUT TO THE PAST}

ABSTRACT: This article analyzes the reform of higher education proposed by the Provisional Measure 746/2016, from the perspective of previous policies, such as those expressed in the Law 5692/1971 and Decree 2208/1997: the merger of curricular branches (by law) or their distinction (by decree) had as function the containment of the demand of higher education. In the case of the provisional measure, this function also stems from a particular crisis in private higher education institutions, which has led to an unprecedented corporate centralization and concentration of capital.

Keywords: Educational policy. Social discrimination. High school. Higher education.

\section{LYCÉE: RACCOURCI VERS LE PASSÉ}

RÉSUMÉ: Cet article analyse la réforme de l'enseignement secondaire proposée par la mesure provisoire n. 746/2016, à la lumière des politiques antérieures, telles que celles exprimées dans la loi 5692/1971 et le décret 2208/1997: la fusion des branches du programme d'études (par la loi)

\footnotetext{
*Texto revisado e atualizado da comunicação do autor no Seminário ANDIFES - Regional Sudeste: Reforma do Ensino Médio, realizado na Universidade Federal do Espírito Santo, Vitória, 8/11/2016. ${ }^{1}$ Universidade Federal do Rio de Janeiro, Faculdade de Educação - Rio de Janeiro (RJ), Brasil. E-mail: contato@luizantoniocunha.pro.br DOI. 10.1590/ES0101-73302017176604
} 
ou sa distinction (par le décret) avait la fonction de confinement de la demande pour l'enseignement supérieur. Dans le cas de la mesure provisoire, cette fonction découle également d'une crise particulière des établissements privés d'enseignement supérieur, ce qui a conduit à une centralisation des affaires sans précédent et à la concentration du capital.

Mots-clés: Politique éducative. Discrimination sociale. Lycée. Enseignement supérieur.

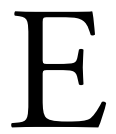

m julho de 1977 , durante a $29^{a}$ reunião anual da Sociedade Brasileira para o Progresso da Ciência, a Sociedade Brasileira de Ensino de Física promoveu uma mesa-redonda sobre política educacional, na qual apresentei a comunicação intitulada "Vestibular: a volta do pêndulo".

Naquela época (já se vão quase 40 anos!), eu participava dos debates sobre a política educacional da ditadura empresarial-militar ainda sob o impulso de dissertação de mestrado defendida cinco anos antes sobre a profissionalização universal e compulsória no Ensino de Segundo Grau, determinada pela Lei no 5.692/1971. Interpretei-a como derivada da política do Ensino Superior, com a função não manifesta de conter a crescente demanda nesse nível. Mostrei que os planejadores da ditadura pretendiam desviar para o mercado de trabalho, supostamente carente de técnicos de nível médio, parte dos jovens que aumentavam ano após ano o número de demandantes de vagas nas universidades públicas, cujos "excedentes" engrossavam as manifestaçóes de descontentes. Esses planejadores supunham que a demanda de técnicos era generalizada e suficientemente grande para absorver os novos diplomados em cursos profissionais. E isso em todos os setores da atividade econômica.

Além da dimensão discriminatória da profissionalização no Ensino de Segundo Grau, a política educacional da ditadura continha outro componente nefasto: a incongruência entre esse nível e o Ensino Superior. Com efeito, a reforma universitária de 1968 trouxe a novidade da divisão dos cursos de graduação em dois ciclos: o básico, comum a grupos de cursos afins, e o profissional, no qual se daria a especialização profissional.

Os problemas da implantação do ciclo básico foram muitos (GARDENAL \& PAIXÃO, 1982). Mas, a incongruência entre sua finalidade precípua de evitar a especialização precoce no Ensino Superior, de um lado; e, de outro, a especialização profissional ainda mais precoce no $2^{\circ}$ Grau não chegou a provocar grandes turbulências por dois fatores. Primeiro, o fato de que as escolas privadas, as principais abastecedoras de calouros para as grandes e boas universidades públicas, ignoraram totalmente a política de profissionalização universal e compulsória no $2^{\circ}$ Grau, e prosseguiram na preparação de vestibulandos. Segundo, as facilidades de expansão do Ensino Superior privado, em instituições universitárias e isoladas, 
que aliviou a pressão sobre as universidades públicas, facilitando a "meia volta, volver!” no Ensino de Segundo Grau.

Novas normas contribuíram para a facilitação do ingresso nos cursos de graduação, como a unificação dos vestibulares por instituição, por curso de mais de uma instituição e até mesmo em âmbito regional, reunindo instituiçóes públicas e privadas, como se fez, pioneiramente, no Rio de Janeiro. De exame, o vestibular passou a concurso, sendo proibida a reprovação de quem obtivesse nota superior a zero; e a redação chegou a ser suprimida.

As críticas à profissionalização universal e compulsória assumiram dimensão política em 1974, quando o partido de oposição recebeu expressiva votação nas eleiçóes legislativas, em âmbitos federal e estaduais - alcançando a maioria no Poder Legislativo de seis estados. A partir de então, os governos dos presidentes militares desenvolveram a estratégia de incorporar demandas parciais das oposições, enquanto modificavam a legislação eleitoral para anular as vantagens que elas iam obtendo, de modo a impedir que conquistassem, desde logo, uma efetiva maioria nas assembleias legislativas e no Congresso Nacional. Daí a distensão do presidente general Ernesto Geisel. Seu ministro da Educação, coronel Ney Braga, não demorou a perceber que a política educacional referente ao Segundo Grau constituía uma fonte geradora de tensóes que cumpria estancar, para o que desencadeou um processo de reforma da reforma do ensino profissionalizante.

A culminância desse processo foi um projeto curto, mas incisivo, oriundo do Ministério da Educação, do qual saiu a Lei no 7.044/1982, determinando que a preparação para o trabalho, no Ensino de Segundo Grau, poderia ensejar habilitação profissional (já não qualificação específica nem compulsória). Tudo ficaria a critério de cada escola, conforme os interesses de professores e alunos (CUNHA, 2005).

Alterou-se, então, a estratégia da "defesa" do Ensino Superior diante do "assalto da massa" de candidatos. Verificada a impossibilidade de diminuir a demanda incidente sobre faculdades e universidades públicas mediante o desvio de parcela significativa de potenciais candidatos para o mercado de trabalho, a solução encontrada foi satisfazê-la com a oferta de cursos superiores de mais baixo valor econômico e simbólico: os cursos de curta duração.

Correlativamente à mudança da política educacional para o Ensino de Segundo Grau — e mesmo antes dela concluir sua inflexão — , verificou-se um renovado esforço governamental para se implementar uma política, já traçada pela reforma universitária de 1968, de multiplicação dos cursos de curta duração, localizados, não no interior das universidades, onde os cursos longos poderiam atrair para si os estudantes dos curtos, mas em estabelecimentos distintos, especialmente em certas escolas técnicas federais.

Essa segregação institucional aliou-se ao combate às semelhanças entre os cursos curtos e os longos. A denominação engenheiros de operação, dada aos 
concluintes de cursos de três anos, foi banida do vocabulário. Eles passaram a ser chamados de tecnólogos. Os cursos deveriam ter currículos bem diferentes dos cursos longos ou plenos, de modo a desestimular futuras tentativas de que os concluintes de uns buscassem "completar" sua formação mediante a adição de umas tantas matérias ao currículo cursado, obtendo, assim, diplomas de cursos longos. É esse o teor do Parecer no 1.589/75 do Conselho Federal de Educação.

Consistentemente com essa nova estratégia, os vestibulares foram redefinidos. De meramente classificatórios que eram, sempre à base de questóes de múltipla escolha (que chegaram a ser obrigatórias), passaram a verificar a habilitação acadêmica dos candidatos. A avaliação da redação em língua portuguesa voltou a ser obrigatória, e as universidades públicas adotaram provas discursivas, apresentadas como melhores do que as "objetivas" na verificação das aptidóes de cada candidato.

Da fusão dos ramos do Ensino de Segundo Grau no governo do general Emílio Médici, passou-se, no governo do ex-professor Fernando Henrique Cardoso, à apartação entre os cursos de Ensino Médio ${ }^{1}$ de caráter geral e os cursos profissionais, a ponto do Decreto no 2.208/1997 suprimir o Ensino Técnico integrado, como o oferecido pelas escolas da rede federal. A integração foi tolerada apenas nas escolas agrotécnicas.

O Ensino Técnico foi definido como independente do Ensino Médio. Isso significava que um aluno poderia cursar o Ensino Técnico exclusivamente ou concomitantemente com o Ensino Médio e até mesmo depois deste.

Em uma situação conflituosa entre o Ministério e o Conselho Federal de Educaçáo, a apartação foi atenuada pela exigência de que o curso técnico somente conferisse certificados para os alunos que também concluíssem o Ensino Médio, ainda que os módulos profissionalizantes fossem obtidos separadamente. Embora os técnicos pudessem candidatar-se a qualquer curso de nível superior, pela letra da lei, a orientação ministerial era o oferecimento de cursos profissionais preferencialmente a estudantes que não conseguissem acesso aos cursos superiores ou tivessem desistido deles como resultado de um mecanismo de autosseleção negativa.

A posse do presidente Lula em janeiro de 2003 abriu caminho para uma nova política no Ensino Médio e no Ensino Técnico. A apartação legal entre ambos foi eliminada e uma ênfase no Ensino Técnico integrado coexistiu com as modalidades concomitante e subsequente ao Ensino Médio. De proibida, a criação de escolas técnicas federais passou a ser prioritária, ao que se somou a expansão das existentes mediante a instalação de unidades descentralizadas.

A função propedêutica do Ensino Médio prevaleceu na política educacional dos governos de Lula e de Dilma, mas uma incongruência entre esse nível e o superior assumiu nova forma com os bacharelados interdisciplinares. Essa modalidade de organizaçáo curricular foi difundida pelo entáo reitor da Universidade 
Federal da Bahia, Naomar de Almeida Filho, que defendeu a edificação do Ensino Superior em três ciclos, na linha do protocolo de Bolonha:

1. o bacharelado interdisciplinar;

2. a formação profissional em licenciaturas ou em carreiras específicas; e

3. a formação científica, artística e profissional na pós-graduação.

O protocolo de Bolonha foi firmado em junho de 1999 por Ministros da Educação de 29 países nessa cidade italiana. Entre eles, estavam os integrantes da Uniáo Europeia e outros que pretendiam ingressar nela. Os signatários assumiram o compromisso de promover reformas no Ensino Superior dos respectivos países com o objetivo maior de elevar a competitividade internacional da Europa. Entre as medidas previstas, estava a adoção de uma organização em três ciclos de estudos: o primeiro, equivalente ao college anglo-saxônico, com a duração de seis a oito semestres; o segundo, com um ano e meio a dois anos, equivalente ao mestrado profissional ou acadêmico; e o terceiro, com duração indeterminada, referente ao doutorado. Com o intuito de facilitar o intercâmbio de estudantes, previu-se o estabelecimento de um sistema de créditos comuns a todos os países signatários.

No Brasil, essa proposta foi parcialmente incorporada pelo Projeto de Lei no 7.200/2016 de reforma do Ensino Superior, elaborado pelo ministro Fernando Haddad. Entre seus dispositivos estava a possibilidade das instituiçóes de Ensino Superior organizarem seus cursos de graduação incluindo um periodo de formação geral, com duração mínima de quatro semestres, para o desenvolvimento de formação humanística, tecnológica e interdisciplinar; para estudos preparatórios aos níveis posteriores de formação; e para orientar a escolha profissional. Ou seja, a criaçáo de um tipo de college de estudos gerais, segundo o modelo anglo-saxônico, que se generaliza na Europa, na esteira do protocolo de Bolonha.

Ao chegar à Câmara dos Deputados, o projeto de lei foi alvejado por mais de 300 emendas, quase todas visando facilitar a criação e o funcionamento de instituiçóes de Ensino Superior privadas, especialmente a diminuição da regulação governamental sobre elas. Atolado nas emendas, o projeto de reforma de todo o Ensino Superior foi abandonado pelo proponente.

Haddad reduziu, então, o âmbito de suas pretensóes e conseguiu do presidente Lula a promulgação do Decreto no 6.096/2007, que criou o Programa de Apoio a Planos de Reestruturação e Expansão das Universidades Federais (REUNI). O decreto apresentou uma lista de meia dúzia de diretrizes para a elaboração do plano de cada universidade, que elas assumiram de boa ou má vontade. Aprovado o plano, cada universidade receberia recursos para construçấo e readequação da infraestrutura e equipamentos; compra de bens e serviços; despesas de custeio e pessoal. 
Dentre as diretrizes do programa, estava a diversificação das modalidades de graduação, preferencialmente não voltadas à profissionalizaçấo precoce e especializada. As novas universidades federais criadas no governo Lula adotaram essa modalidade de ensino. As federais mais antigas enxertaram cursos com tais características no seu elenco de cursos de graduação profissionais e disciplinares.

A meu ver, a adoção do college anglo-saxônico, diretamente ou com escala em Bolonha, não é, em si mesma, boa nem má. Depende de como é feita. Se vier apenas como um enxerto na estrutura de nossos cursos de graduação, será mais um fracasso entre tantos outros que castigam a educação brasileira. A substituição da graduação especializada, vigente no Brasil há 200 anos, por um sistema baseado no college pode vingar, mas não à base de enxertias. Seria necessário algo muito mais amplo, que abrangesse o conjunto dos cursos e a regulamentação profissional, inclusive os organismos corporativos, sem esquecer a mentalidade inercial das burocracias públicas e privadas como empregadoras.

A tendência mundial é para cursos de graduação mais curtos do que os quatro anos modais do Brasil e mais gerais do que os nossos, mas a realidade nacional precisa ser levada em conta com seriedade e ser objeto de estudos aprofundados de viabilidade. Portugal e Espanha estáo amargando as consequências da adaptação ao protocolo de Bolonha. Todavia, os efeitos lá serão menos drásticos do que seria no Brasil, porque esses países mantiveram escolas públicas de Educação Básica de boa qualidade, pelo menos não tiveram a deterioração da qualidade ou a expansão da precariedade que se observa entre nós.

Náo bastasse essa preocupação com o Ensino Superior, surge agora outra, e agravante, a reforma do Ensino Médio pretendida pela Medida Provisória $\mathrm{n}^{\mathrm{o}} 746$, de 22 de setembro de 2016, o primeiro ato direto do governo Temer no campo educacional ${ }^{2}$.

Ela determinou a mudança da estrutura e do currículo do Ensino Médio nas escolas públicas e privadas. Em vez de um currículo comum a todos, como definida na Lei de Diretrizes e Bases da Educação Nacional e na primeira versão da Base Nacional Curricular Comum para a Educação Básica (BNCC), a medida provisória instituiu cinco itinerários formativos especificos no Ensino Médio: Linguagens, Matemática, Ciências da Natureza, Ciências Humanas e Formação Técnica e Profissional ${ }^{3}$. Com a argumentação de que o Ensino Médio tem muitas disciplinas e não atrai o interesse dos estudantes, pretendeu-se agrupar disciplinas em cursos diferentes, que os alunos escolheriam depois de terem passado por certa dose de estudos comuns. Quatro disciplinas integrantes do Ensino Médio e da BNCC em discussão teriam a obrigatoriedade suprimida para todos: Artes, Educação Física, Filosofia e Sociologia. Para atenuar o efeito negativo das supressóes, o ministro Mendonça Filho prometeu que a BNCC e cada escola determinarão as disciplinas obrigatórias em cada itinerário. Para todos os alunos, somente Linguagens (Português e Inglês) e Matemática. Ou seja: a medida provisória jogou 
a especificação para a BNCC, que, por sua vez, aguarda a decisão do Congresso sobre a medida provisória, em um processo de causação circular cumulativa que revela a falta de coerência na política educacional para o Ensino Médio ${ }^{4}$.

A medida provisória incorporou quase tudo do Projeto de Lei $\mathrm{n}^{\mathrm{o}}$ 6.840/2013, apresentado pelo deputado Reginaldo Lopes (PT-MG). A diferença é que ele se mostrou sensível às críticas que seu projeto recebeu do Ministério da Educação do governo Dilma e do Movimento Nacional em Defesa do Ensino Médio, e elaborou um substitutivo, ainda durante a tramitação na Comissão de Educação. As opçóes formativas (na medida provisória, itinerários formativos especificos) do substitutivo não eram obrigatórias. Os alunos poderiam seguir o currículo completo do Ensino Médio ou tais opçóes e, mesmo assim, quando houvesse regime de jornada estendida, chamada de integral.

Quando o projeto de lei estava pronto para ir ao plenário, foi atropelado pela medida provisória. Na realidade, o que ela atropelou foram as demandas generalizadas do campo educacional. Até mesmo defensores da flexibilização do Ensino Médio rejeitaram a chegada da reforma ao Congresso como medida provisória, portanto, com validade imediata, e seu conteúdo propiciador de acirramento das desigualdades educacionais e sociais.

Não se trata de invenção de ministro improvisado. Trata-se, isto sim, da reedição da política educacional discriminadora do período Fernando Henrique Cardoso, quando Maria Helena Guimarães de Castro ocupou a presidência do Instituto Nacional de Estudos e Pesquisas Educacionais durante toda sua gestão, após dirigir secretarias nos governos paulistas de José Serra e Geraldo Alkmin. Ela retornou ao Ministério da Educação no governo Temer, agora como secretária geral. A concepção da Medida Provisória no 746/2016 é de sua autoria, evidenciada na separação entre o Ensino Técnico e o Ensino Médio, apartação dissimulada nos itinerários formativos especificos - quatro propedêuticos e um terminal. Retorna, assim, a antiga concepção do Ensino Médio como preparação para o Ensino Superior para uns, e formação para o trabalho para outros.

Se atentarmos para a articulação com os cursos superiores, veremos que essa discriminação assumirá uma configuração especial. Na prática, e na melhor das hipóteses, para os egressos da Formação Técnica e Profissional restarão os cursos tecnológicos, mais curtos e específicos; para os demais, cursos profissionais plenos e os bacharelados interdisciplinares. Pode-se divisar uma correspondência com a formatação da educação brasileira na legislação concebida por Gustavo Capanema durante o Estado Novo. Com efeito, cada "lei" orgânica referia-se à articulação do ramo de ensino em questão com o superior. Até então, não havia possibilidade para concluintes de cursos não secundários se candidatarem aos exames vestibulares. Depois delas, os egressos de cursos médios profissionais passaram a ter acesso muito restrito ao Ensino Superior, podendo se candidatar apenas aos cursos relacionados com os que haviam feito. Os concluintes do segundo ciclo do ramo secundário jamais tiveram restriçóes de candidatura. 
Se não se trata de uma improvisação de ministro improvisado, qual é a lógica da política educacional expressa na Medida Provisória no 746/2016? Apresento a hipótese de que ela resultou da retomada da função "contenedora" atribuída ao Ensino Médio. Tudo parece indicar que a explicação dessa política se encontra não no Ensino Médio, propriamente, mas no Ensino Superior, como nas reformas das décadas de 1970 e 1990. Exploro essa hipótese mediante duas vertentes: a crise da expansão do setor privado do Ensino Superior, que vinha do segundo governo Dilma, e o acirramento dessa crise já no governo Temer, principalmente pelo estreitamento do financiamento governamental.

Há alguns anos o segmento privado do Ensino Superior está em crise. Depois de vários anos de acelerado crescimento, para o que não faltou apoio governamental, as falências de faculdades, centros universitários e até de universidades levaram a uma concentração institucional sem precedentes. Grandes grupos se formaram a partir de capital nacional e internacional, absorvendo pequenas e médias instituições. Agora, até as grandes se fundem e disputam o mercado.

A história da centralização empresarial, resultado da concentração do capital, apresenta um amplo gradiente de casos de sucesso e insucesso, nem sempre vantajosos para docentes e estudantes.

Comecemos com um caso de sucesso, o da Kroton Educacional. A origem desse grupo está no curso pré-vestibular Pitágoras, de Belo Horizonte, criado em 1966. O cursinho evoluiu para o Ensino de Primeiro e Segundo Graus regular, tanto no Brasil quanto no exterior, tirando proveito do deslocamento de trabalhadores de empresa de construção sediada em Minas Gerais, contratada para obras no Oriente Médio e na África. Posteriormente, o grupo atuou com alunos brasileiros no Japão e no Canadá, mediante escolas conveniadas. O Pitágoras ingressou no mercado de sistemas apostilados de ensino e, em 2000, passou a atuar no Ensino Superior, adquirindo instituiçóes preexistentes. Em 2007, abriu o capital e ingressou na bolsa de valores com o nome de Kroton Educacional, o que lhe permitiu receber forte injeção de capital do fundo de pensão Advent International. Três anos depois, a Kroton incorporou a Universidade de Cuiabá, a União Metropolitana de Educação e Cultura, na Bahia, e a Escola Superior de Marketing, em Pernambuco. Outros dois anos se passaram e o grupo absorveu o Centro Universitário Cândido Rondon, em Mato Grosso, e a Associação Educacional Leonardo da Vinci, em Santa Catarina. Em 2013, foi a vez da Universidade do Norte do Paraná e da Universidade Anhanguera, em São Paulo. Estava, assim, formada uma empresa holding, com um milhão de estudantes, 123 unidades de ensino presencial, além de polos de ensino a distância e escolas de educação básica associadas, tudo isso com mais forte presença na região sul do país. Estimativas divulgadas na época da fusão com a Anhanguera calculavam seu valor de mercado como o maior do mundo no setor - 6,3 bilhóes de dólares, o dobro da segunda, a chinesa New Oriental, e quase três vezes superior à terceira colocada, a Universidade Estácio de Sá, sediada no Rio de Janeiro. 
A compra dessa universidade carioca, com maior presença no sudeste e no nordeste, foi disputada pela Kroton Educacional e pelo grupo Ser Educacional, o qual, partindo da Faculdade Maurício de Nassau, em Recife, crescera a ponto de incorporar a Universidade de Guarulhos, na área metropolitana de São Paulo. A oferta da Kroton foi vencedora, de modo que o grupo resultante passou a abranger um efetivo superior a um milhão e meio de estudantes e atuação em todo o território nacional.

Mas nem sempre a centralização empresarial e a concentração do capital resultam em tamanho sucesso empresarial. A empresa Galileo Educacional exemplifica um caso de fracasso.

Criada em 1972, a Universidade Gama Filho foi a primeira instituição universitária privada não confessional do Brasil, derivada de um estabelecimento de Educação Básica gerido pela família que deu nome à instituição e que mantinha o controle patrimonial. As dificuldades de adaptaçáo da gestáo familiar/ patrimonialista aos padróes capitalistas que o mercado impunha, especialmente pelo crescimento do número de cursos, de professores e de estudantes, levou a universidade a acumular grandes dívidas.

Em 2010, um professor da universidade criou a empresa Galileo Educacional, e obteve da família que controlava a Universidade Gama Filho a transferência da instituição de Ensino Superior para essa nova mantenedora. Com recursos obtidos de fundos de pensáo de empresas estatais, a Galileo adquiriu o Centro Universitário da Cidade do Rio de Janeiro, que também se encontrava em dificuldades financeiras. Para enfrentar as dívidas das duas instituições, a redução de atividades foi a saída escolhida. Unidades foram fechadas, cursos cancelados, mensalidades aumentadas e pessoal docente e administrativo demitido, mas os problemas financeiros continuaram. Em 2012, o fracasso na gestão das duas instituições levou a Galileo Educacional a passar para o controle de um pastor evangélico, empresário bem-sucedido, mas sem experiência no setor. Em 2013, estudantes, professores e funcionários entraram em longa greve, e a mantenedora firmou com o Ministério da Educação um termo de compromisso de saneamento de deficiências. Náo obtendo respostas positivas, no fim desse ano, o Ministério suspendeu os vestibulares das duas instituiçóes e instaurou inquérito administrativo, que resultou, em janeiro de 2014, no descredenciamento da Universidade Gama Filho e do Centro Universitário da Cidade do Rio de Janeiro, o que atingiu cerca de 10 mil alunos, 1,6 mil professores e 3 mil funcionários. Diante da crise acadêmica, os reitores das universidades federais sediadas no estado do Rio de Janeiro apoiaram a proposta das entidades sindicais de federalização das duas instituiçôes, o que, todavia, não foi aceito pelo ministério.

O desfecho dessa crise foi o fim de uma universidade e um centro universitário, ao que se seguiu a falência da Galileo Educacional, determinada por decisão judicial em 2016. Os estudantes obtiveram documentos para transferência para outras instituiçóes de Ensino Superior e os professores e funcionários, sem os empregos, aguardam o recebimento dos salários atrasados. 
A segunda vertente da análise é a do financiamento governamental, particularmente o Fundo de Financiamento Estudantil do Ensino Superior (FIES) 5 . Criado em 1999, o fundo realizou mais de dois milhóes de contratos de financiamento de mensalidades de cursos de graduação, sendo os de Administração, Direito e Enfermagem os mais procurados, abrangendo um terço das bolsas de $2016^{6}$. No governo Dilma, além do aumento de recursos para o fundo, as condiçôes de financiamento foram facilitadas: os alunos já não precisaram de fiador, o prazo de pagamento foi dilatado e a taxa de juros, reduzida. Em 2015, foram firmados 300 mil contratos, cifra que dá a dimensão dessa fonte de financiamento para os estudantes de baixa renda, mas, também, para as instituiçóes de Ensino Superior, já que parte dos beneficiados deixaria os cursos mais cedo ou talvez nem mesmo neles ingressassem caso tais bolsas não existissem. Além disso, a facilitação das condiçóes de financiamento levou as instituiçôes de ensino a aumentarem as mensalidades, já que elas tinham o recebimento garantido pelo governo. A resistência dos alunos pagantes foi contornada por sua inserção nas vagas disponíveis do FIES (SALDAÑA, 2017).

Mas a crise econômica atingiu em cheio o setor privado do Ensino Superior, sobretudo devido ao agravamento das condições de vida dos estudantes, obrigando muitos deles a abandonarem os cursos, mesmo quando beneficiados por algum tipo de bolsa. $\mathrm{O}$ resultado foi a drástica redução do número de calouros com bolsas do FIES: em 2014, eles eram 38\% do alunado das instituiçóes privadas, proporção que caiu para $19 \%$ em 2015 , ou seja, para a metade. Os alunos pagantes, por sua vez, não ficaram imunes à crise que atinge as famílias da baixa classe média, notadamente o desemprego. Tudo isso resultou em uma taxa de inadimplência, em 2016, da ordem de 50\% dos contratos. E essa crise ficou ainda pior em decorrência das políticas econômica e educacional do governo Temer. ${ }^{7}$

Consistentemente com a reforma constitucional que congelou por 20 anos as despesas governamentais (salvo para o pagamento de juros da dívida), o Ministério da Educação freou os gastos com o FIES. O número de vagas para 2017 foi reduzido para um patamar igual à metade de 2015, ou seja, para $150 \mathrm{mil}$ novos alunos. E o teto do valor de mensalidade a financiar foi reduzido para $\mathrm{R} \$ 5$ mil, o que atinge os cursos de Medicina, que praticam valores acima dele.

Não bastasse isso, a Medida Provisória no 741, baixada em julho de 2016, transferiu, do Fundo Nacional de Desenvolvimento da Educação para as instituiçóes privadas, os encargos financeiros bancários das bolsas do FIES. Além da redução da receita certa, provinda dessas bolsas, as instituiçóes privadas de ensino passaram a arcar com o aumento das despesas devido aos encargos financeiros nelas implicados.

A direção desse processo é a privatização do financiamento estudantil, para o que o ministro Mendonça Filho tem acenado em seus pronunciamentos. Antecipando-se às decisóes governamentais, a Kroton já se prepara para financiar as mensalidades de seus alunos, por meio de banco próprio. 
Retomando, então, o raciocínio desenvolvido neste artigo, temos que a contenção da demanda de Ensino Superior foi a explicação da Medida Provisória no 746/2016, complementada com a redução do financiamento estudantil mediante o FIES, em volume de recursos/vagas e transferência para as instituiçóes privadas dos encargos financeiros até então assumidos pelo governo.

Política educacional "contenedora” no Segundo Grau/Ensino Médio, para desviar demanda do Ensino Superior, já tivemos na ditadura e no octênio Fernando Henrique Cardoso. Estamos destinados a repetir o passado? Presumo que pode ser ainda pior do que isso. Durante a ditadura, não faltaram propostas de transferência das universidades públicas para o setor privado, pelo menos para que elas passassem a cobrar mensalidades a preço de mercado. Tais propostas náo se concretizaram devido à grande resistência de estudantes e professores, assim como pelo aumento da oferta de vagas nas universidades e faculdades privadas. Hoje, o caldo de cultura ideológica favorece a adoção de tais medidas, que podem funcionar como contraponto à penalização das instituições privadas, que perderam parte das benesses do FIES. Com efeito, a cobrança de mensalidades pelas universidades públicas (para o que seria preciso uma reforma da Constituição) reduziria parte de suas vantagens comparativas diante das privadas, que poderiam atrair para estas um maior número de candidatos capazes de pagar seus cursos de graduação.

\section{Notas}

1. A Lei de Diretrizes e Bases da Educação Nacional alterou a nomenclatura dos níveis de ensino, de modo que o Segundo Grau foi redenominado Médio.

2. Depois de alterada na Câmara dos Deputados em tópicos não essenciais, a Medida Provisória foi aprovada no Congresso Nacional e sancionada pelo presidente Temer como Lei $\mathrm{n}^{\circ} 13.415$, em 16 de fevereiro de 2017.

3. Ao passar pela Câmara dos Deputados, os itinerários formativos Linguagens, Matemática e Ciências da Natureza receberam o complemento "e suas tecnologias", expressão buscada em antiga diretriz curricular do Conselho Nacional de Educação para o Ensino Médio. O itinerário referente às Ciências Humanas foi acrescido das Sociais Aplicadas.

4. A Câmara dos Deputados repôs a obrigatoriedade de Arte e determinou que a base nacional comum curricular inclua estudos e práticas de Educaçáo Física, Arte, Sociologia e Filosofia - assim mesmo, vagamente.

5. O objetivo do fundo é financiar o pagamento das mensalidades de estudantes de graduação de baixa renda em instituiçôes privadas. O Bando do Brasil e a Caixa Econômica Federal são os agentes dos recursos do fundo, oriundos do orçamento do Ministério da Educação e das restituiçóes realizadas pelos beneficiados. Na distribuição das bolsas, o fundo prioriza os alunos dos cursos de formação de professores, as engenharias e os da área de saúde. Além desses, são priorizados os alunos de cursos situados em municípios de baixo Índice de Desenvolvimento Hu- 
mano. O valor correspondente ao pagamento das mensalidades de cada aluno bolsista é creditado diretamente à instituição de ensino. Após a conclusão do curso, o beneficiado tem 18 meses de carência, após o qual assume o encargo de pagar o empréstimo em um período igual a três vezes a duração do mesmo. Embora prioritários, os cursos de formação de professores não estiveram entre os mais procurados pelos estudantes interessados no financiamento.

6. A "ponte para o futuro", documento que expôs a plataforma do governo Temer, antes mesmo dele assumir a Presidência da República, priorizava o fim de subsídios e a revisão na abrangência de programas sociais, com o objetivo de alcançar o equilíbrio fiscal. Para detalhamento dessa plataforma, que justifica as mudanças no FIES, ver PMDB (2015).

\section{Referências}

CUNHA, L.A. O ensino profissional na irradiação do industrialismo. São Paulo: Editora da Unesp, 2005. 270 p.

GARDENAL, L.; PAIXÃO, A.L. Ciclo básico na universidade brasileira: temas e problemas principais. Cadernos de Pesquisa, Sáo Paulo, v. 41, p. 3-11, maio 1982.

PARTIDO DO MOVIMENTO DEMOCRÁTICO BRASILEIRO (PMDB). Uma ponte para o futuro. Brasília, 29 out. 2015. Disponível em: <http://pmdb.org.br/wp-content/ uploads/2015/10/RELEASE-TEMER A4-28.10.15-Online.pdf $>$. Acesso em: 1. ${ }^{\circ}$ nov. 2016.

SALDAÑA, P. Inadimplência aumenta, e mais de metade atrasa pagamento do Fies. Folha de S.Paulo, 29 jan. 2017. p. B-1.

Recebido em 04 de março de 2017.

Aprovado em 12 de abril de 2017. 